\title{
A Validation Study of the What's My School Mindset?
}

\section{Survey}

\author{
Janet Hanson (Corresponding author) \\ Department of Educational Leadership, Montana State University (MSU) \\ 457 Reid Hall, Bozeman, Montana, USA \\ $\&$
}

Educational Leadership Department, Azusa Pacific University

P.O. Box 7000, Rm 137, Azusa, CA 91702-7000, USA

Tel: 1-(626)-815-5375 E-mail: jhason@apu.edu

\begin{abstract}
Arthur Bangert
Department of Educational Leadership, Montana State University (MSU)

115 Reid Hall, Bozeman, Montana, USA
\end{abstract}

Tel: 1-(406)-994-7424 E-mail: abangert@montana.edu

\begin{abstract}
William Ruff
Department of Educational Leadership, Montana State University (MSU) 457 Reid Hall, Bozeman, Montana, USA
\end{abstract}

Tel: 1-(406)-994-4182Ｅ-mail: wruff@montana.edu

Received: October 3, 2016 Accepted: October 28, 2016

Published: November 3, 2016

doi:10.5296/jei.v2i2.10138 URL: http://dx.doi.org/10.5296/jei.v2i2.10138

\begin{abstract}
The What's My School Mindset? (WMSM) survey is purported to operationalize teachers' beliefs of their school's ability to help all children learn and grow. In today's data driven educational climate it is important to select a reliable instrument for collecting teacher
\end{abstract}


perceptions about their school culture. Accurate data is necessary to support development of realistic continuous improvement goals and to measure progress toward those goals. This study collected teacher and administrator responses $(n=348)$ from a stratified random sample of 31 PK-12 public schools in a large northwestern state. A split-half exploratory factor analysis $(\mathrm{n}=$ 178) was used to identify a proposed factor structure model. The proposed model was tested using the second half confirmatory factor analysis sample $(n=174)$ and confirmed the model revealing school mindset is a second order, unidimensional factor with three subfactors. The results of this study are useful for school leaders and researchers who seek to use the What's My School Mindset? scale to measure growth mindset within a school's culture. Accurately interpreting the measurement of one's school culture can increase administrator effectiveness and provide a foundation for opening realistic dialogues with teachers about their self-reported beliefs. A useful discussion of the background of school growth mindset, development of the What's My School Mindset? instrument, and theoretical framework of learning organization theory is provided.

Keywords: Mindset, School culture, Administrator effectiveness, Teacher attitudes, Survey

\section{Measurement of Psychosocial Factors}

Assessment measures in schools have largely focused on cognitive variables demonstrating learning outcomes of student and school effectiveness. However, Weschler (1943), developer of the famed IQ measurement scale stated, "there are also definite non-intellectual factors which determine intelligent behavior" (p. 103). Psychosocial factors have been suggested for use as growth markers of individual and school learning and for meeting accountability requirements (Adams, 2014; Dweck, 2010; Farrington et al., 2012). Interventions based on reliable psychosocial data that supports improved school cultures, and all students in their efforts to succeed, would be useful to PK-12 public school administrators (Dweck, 2010; Hoy, Tarter, \& Kottkamp, 1991; Kearney, 2007; Mindset Works, Inc., 2015a-2015c; Panorama Education, 2014; Walton, 2014). The challenge for measuring such factors begins with the development of operational definitions that are quantified on a scale that is valid and reliable. Duckworth and Yeager (2015) explained, "Scientific inquiry and organizational improvement begin with data collection" (p. 29).

\subsection{Background of a Scale to Measure School Mindset}

Mindset Works, Inc. website provides several survey tools to measure the psychosocial construct of a growth mindset. A "team of researchers, curriculum specialists and educators with experience in mindset and its application" worked to develop a 20-item, Likert-style survey to assess a school's mindset culture. (S. Rodriguez, personal communication, March 31, 2015). What's My School Mindset? (WMSM) instrument is purported to operationalize five key features of a school growth mindset culture including: shared leadership, open communication, professional collaboration, clear goals and school plan, and support for and belief that all students can grow and learn (Blackwell, 2012). Teachers and administrators provide self-reports of their school culture and Mindset Works, Inc. (2015a-2015c) then uses the results of the survey to make recommendations for intervention curriculum, faculty training, and products directed at developing a growth mindset culture in schools (para. 1-11). 


\subsection{Purpose Statement}

The purpose of this research study was to explore the factor structure of the WMSM scale and to add to the understanding of the relationships between items on the scale. The results of this study may provide insights into variables that contribute to improved school cultures and additional paths for administrators to help faculty develop the belief they can help all students learn and grow.

\subsection{Problem Statement}

Director of Research \& Implementation Sylvia Rodriguez at Mindset Works, Inc., in a personal communication (October 14, 2014) explained the current version of the WMSM scale had not undergone empirical studies to provide validity evidence in support of the factor structure. For those using the instrument, an understanding of the underlying constructs purported to be quantified in the WMSM scale is important for an accurate interpretation of the scale results, for drawing valid conclusions, and for determining school specific interventions.

\subsection{Research Question}

The overarching research question of this study was "What is the underlying factor structure of the WMSM scale?" And the following null hypothesis was tested:

$\mathrm{H}_{0}=$ The five-factor structure of shared leadership, open communication, professional collaboration, clear goals and school plan, and support for and belief that all students can grow and learn does not represent the underlying factor structure for the WMSM scale.

\section{Literature Review}

Mindset theory is situated in the social cognitive model of motivation and learning. Current research revealed the organization, or group such as a school, has a powerful influence on whether the learner experiences internal or external locus of control as described in Bandura's social cognitive theory. Bandura $(1977,2001)$ explained that the well-being of the individual depended on individual goal alignment with the system's goals (Hanson, in press). In school cultures, collective efficacy was described as the faculty's belief about the capacity of the entire staff to work together to achieve positive effects on students. This concept is closely related to the WMSM scale's item number 20 operationalized definition of a school growth mindset. A leaders' organizational citizenship behaviors in schools also explained improvements in school climate (DiPaola \& Hoy, 2005; DiPaola \& Tschannen-Moran, 2001). These psychosocial supports are consistent with the five features of a growth mindset school culture (Blackwell, 2012; Mindset Works, 2015a-2015c).

Implicit theories of fixed or incremental mindset have been shown to predict self-regulatory processes of goal setting, similar to constructs of human agency (Baumeister, Masicampo, \& Vohs, 2011; Hong, Morris, Chiu, \& Benet-Martínez, 1999; Martin, 1979). Effective school leaders, using mindset interventions, understand the importance of goal alignment between individuals and the organization (Burnette, O'boyle, Vanepps, Pollack, \& Finkel, 2013; Woike, 2008). A review of the literature revealed the five features purported to be 
operationalized on the WMSM scale compare favorably with organizational learning and learning organization models that are considered critical contributors to the organizational health of schools (Blackwell, 2012; Dweck, 2012; Bandura, 2001; Senge, 2000; Tarter \& Hoy, 2004).

\subsection{Model of Learning Organizational Variables}

Thomas and Allen (1994) found in a meta-analysis of learning organization literature that learning occurs at three levels; individual, team, and system levels. Figure 1 provides a comparison and contrast of key features of learning organization variables identified at the individual, team, and system levels of the organization found in Senge's Five Disciplines (2000) model, Tarter and Hoy's (2004) Open Systems engaging school structures model, and Mindset Works, Inc.'s (2015a-2015c) school growth mindset model.

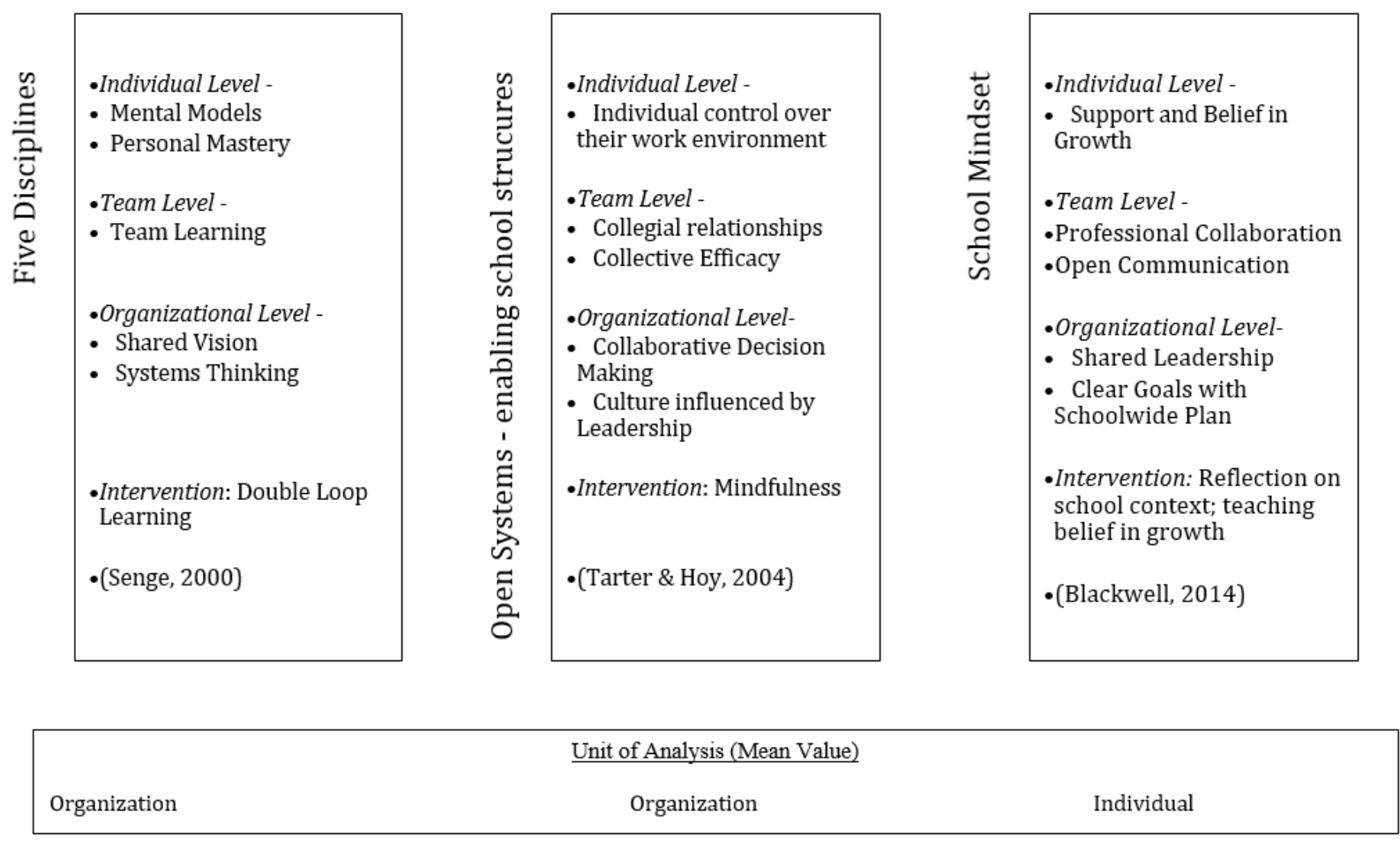

Figure 1. Table of comparable and contrasting learning organization variables with school mindset (Hanson, 2015)

The above figure shows factors of enabling school structures and system's thinking with the five-features described as operationalizing the school mindset construct.

\subsection{The Five Disciplines}

In the Five Disciplines model, a learning organization included the following key disciplines: personal mastery, mental models, shared vision, team learning, and systems thinking. Under the Five Disciplines model the primary activity of the leader was to provide interventions that 
promoted the development of the school as a learning organization. Senge (1990) explained:

... people are agents, able to act upon the structures and systems of which they are a part. All the disciplines are, in this way, 'concerned with a shift of mind from seeing parts to seeing wholes, from seeing people as helpless reactors to seeing them as active participants in shaping their reality, from reacting to the present to creating the future' (p. 69).

This review identified Senge's 2nd Discipline, mental models, as similar to Dweck's (2006, 2012) model of mindset. Senge (2000) explained individuals generate their beliefs, from inference, through experience. He recommended the processes of reflection and inquiry as necessary for individuals to continually reconstruct and correct their mental models. Senge explained that without reflection and inquiry an individual's mental model might result in bias and incorrect constructs through a process he described as the "ladder of inference" ( $p$. $68,69)$. Organizational learning in this model is the development of improved shared mental models. The concepts of individual mental models, the use of reflection, and a collaborative network within the organization compare favorably with the concepts of individual and school mindset.

\subsection{Open Systems Model}

A theory of Open Systems, referred to as General Systems Theory (GST), dates back to Von Bertalanffy (1950), who described an 'organismic' model of social phenomena as integrated wholes. He used the term equifinality to explain that the final state of the open system may be reached from different starting points and in different ways, and was "the main proof of vitality" (p. 25). The model of an open system included not only processes but the values of the participants concerning "the[ir] relationship ... to the world, that is, humans to humans, humans to nature, humans to technology" (Hofkirchner, n.d., para. 3). This definition closely aligns with Blackwell's (2012) description of a school growth mindset culture, defined as a combination of values, norms, and behaviors of teachers and administrators who believe they can help all students learn and grow.

An "open climate" in an organization is when individuals demonstrate cooperation, respect, and openness between the individual faculty members and the faculty and the principal. Researchers tested the validity of the Open Systems model by showing certain critical internal elements of an organizational system positively correlated with school effectiveness. The model described factors of an enabling school structure including: principals and faculty working together as colleagues; the individual's desire to gain control over his work environment and the influence this had on motivation; the culture of the organization influenced by the leadership style of the principal; and the way administrators made decisions (Tarter \& Hoy, 2004, p. 540). School mindset correlated significantly with engaging school structure variables and explained variation in the WMSM mean scores (Hanson, Ruff, \& Bangert, 2016; Leithwood, Anderson, Louis, \& Wahlstrom, 2004; Spencer-Rodgers, Williams, \& Peng, 2012; Strahan, Spencer, \& Zanna, 2002).

\section{Study Design and Methods}

This was a quantitative survey validation study designed to explore the factor structure of the 
What's My School Mindset Scale (Mindset Works, Inc., 2015c). The data collected from teachers and administrators was randomly split into two groups. An exploratory factor analysis was performed using SPSS on one half of the data $(\mathrm{n}=176)$ and a proposed model developed from the data. The second group, the cross validation sample $(\mathrm{n}=176)$, was used for a confirmatory factor analysis using Lisrel (9.2) (Jöreskog \& Sörbom, 2015).

\subsection{Participants}

The participants included faculty and administrators $(\mathrm{n}=348)$ from a random, stratified sample of 31 PK-12 schools across a large northwestern state with a mostly rural demographic. The sample was selected from 417 school districts, including 10,153 teachers and 142,349 students, during the 2014/2015 school year (Meador, 2015). An approximate stratified random sample of schools by class size was selected using a random number generator to obtain a representative sample.

\subsection{Instrument}

The 20-item Likert-style WMSM scale used in this study asks respondents to rate their level of agreement on items using a scale ranging from $1=$ Strongly Disagree, $2=$ Disagree, $3=$ Somewhat Disagree, 4 = Somewhat Agree, 5 = Agree, and $6=$ Strongly Agree. Items 6, 8, 10, and 19 were reverse coded. Item wording is provided in Table 1 in the Results section.

\section{Results}

Three hundred and forty-eight usable responses were returned yielding a 95\% confidence level and a 5.16 percent confidence interval for the population of teachers and administrators completing the WMSM instrument. Criteria by Guilford (1954) and Zhao (2009) indicate that the 348 participants for this study are more than adequate for instrument development research. The ratio of participants to items is 18 to 1 and considered adequate for analyzing the WMSM items using factor analysis (Field, 2000). Prior to performing the exploratory factor analysis, the data collected was examined to evaluate the assumptions of normality and for missing data. The purpose of these analyses was to identify issues with the data that might adversely impact the exploratory and confirmatory factor analysis (Jöreskog, 1999; Netemeyer, Bearden, \& Sharma, 2003). Results from the Shapiro-Wilks test found that data for each item was significantly skewed in the positive direction of the distributions. This condition is not unusual for ordinal data. According to Fabrigar, Wenger, MacCallum, and Strahan (1999), factor analytic procedures that employ maximum likelihood estimates are not adversely affected when skewedness of the variables is less than 2.00 and kurtosis is not greater than 7.00. Additionally, Byrne (1998) points out that nonnormal data does not adversely affect estimation if all the distributions of the items that comprise the model are skewed in the same direction. Results for the Bartlett's Test of Sphericity was found to be significant indicating that the items, although correlated, were not correlated so highly as to produce an identity matrix preventing the factor analysis from successfully reducing the data into interpretable factors. 


\subsection{Items Removed}

Due to the ordinal characteristics of the data, polychoric correlations were entered into SPSS to conduct the exploratory factor analysis. Results of the exploratory factor analyses yielded three interpretable factors accounting for a total of 55\% of the total variance of the data structure. Eighteen of the 20 items from the WMSM were retained. Item 20, "There is a culture of continuous improvement where we are constantly looking at our current state and setting improvement goals year-to-year" was eliminated from the analysis due to correlations exceeding .80 with three other WMSM items. Item 18, "There are structures for teachers and administrators to share information and work together to meet the specific needs of individual students" was captured by factor 1, though was removed due to cross loading with factor 3 , open communication and support. The most interpretable factor pattern yielded a three-factor solution using maximum likelihood extraction and oblique rotation methods. Each of the three factors consisted of at least three items, exhibited factor loadings $<.80$ and $>.30$ and had items that were minimally cross-loaded with items in other factors (Brown, 2009; Field, 2009; Gravetter \& Wallnau, 2014). Stevens (2002) suggests that item loadings should differ by at least .200 to be interpreted as not cross-loaded with other factors.

\subsection{Exploratory Factor Analysis}

The following section describes the results of the exploratory factor analysis and the proposed three-factor model of a growth school mindset, quantified on the WMSM scale, and tested by the confirmatory factor analysis in this study. The three factors were named in this study as collaborative planning (CP), shared leadership (SL), and open communication \& support (OCS).

\subsubsection{Collaborative Planning}

The first factor to emerge was interpreted as collaborative planning (CP). Collaborative planning was comprised of items $11-16$ and contributed $47 \%$ of the total variance explained by the three factor model. The items comprising this factor all related to formal structures within the system providing opportunities for teachers and administrators to collaborate through observation, shared planning, and feedback to improve instruction.

\subsubsection{Shared Leadership}

The second factor, shared leadership (SL), captured items 1-5 and contributed to $4.6 \%$ of the total variance. The items included in this factor related to teacher and administrator engagement in collaborative decision-making processes.

\subsubsection{Open Communication \& Support}

The third factor consisted of items 6-10, 17 and 19 and was interpreted as open communication \& support (OCS). This factor contributed approximately $3.5 \%$ of total variance explained by the three-factor model. The items were related to teachers and administrators' informal activities to support student instruction and individual goals. 


\subsubsection{Scale Reliabilities}

The internal consistency reliabilities for all three factors were found to range from .72 to .88 , with a full-scale internal consistency reliability of .92. The factor loadings, item means, standard deviations, and reliabilities are reported in Table 1.

\subsection{Confirmatory Factor Analysis}

The second random half of the sample was then subjected to a confirmatory factor analysis, using Lisrel 9.2 (Jöreskog \& Sörbom, 2015), to crossvalidate the three-factor structure identified by the exploratory analysis. This analsysis was performed to determine if the three-factor model identified by the exploratory analysis was a good fit for the hypothesized three-factor population model. Several indices of model fit were used to evaluate the results. The Root Mean Square Error of Approximation (RMSEA) is currently recognized as an informative index of fit because it provides a value that describes the discrepancy, or error, between the hypothesized model and an estimated population model derived from the sample. RMSEA values less than .05 are indicative of a close fit, values ranging from .05 to .08 are indicative of a reasonable fit, with values $\geq .9$ considered a poor fit (Browne \& Cudek, 1993; MacCallum, Browne, \& Sugawara, 1996). 
Table 1. Individual item factor loadings, significance, percentage of variance, and eigenvalues for items on the WMSM scale

\begin{tabular}{|c|c|c|c|c|c|}
\hline \multirow[b]{2}{*}{ Items } & \multicolumn{3}{|c|}{ Factors } & \multirow[b]{2}{*}{$M$} & \multirow[b]{2}{*}{$S D$} \\
\hline & $\begin{array}{l}\text { Collaborative } \\
\text { Planning } \\
\text { (CP) }\end{array}$ & $\begin{array}{l}\text { Shared } \\
\text { Leadership } \\
\text { (SL) }\end{array}$ & $\begin{array}{l}\text { Open } \\
\text { Communication } \\
\text { \& Support (OCS) }\end{array}$ & & \\
\hline $\begin{array}{l}\text { 12. Administrators communicate a sincere belief } \\
\text { that staff members can develop their teaching } \\
\text { skills with practice and feedback. }\end{array}$ & .745 & -.099 & .068 & 4.56 & 1.11 \\
\hline $\begin{array}{l}\text { 15. Teachers receive professional development } \\
\text { that is targeted to their professional needs and } \\
\text { goals. }\end{array}$ & .698 & -.017 & -.024 & 4.14 & 1.31 \\
\hline $\begin{array}{l}\text { 14. Teachers, coaches, and administrators work } \\
\text { together to design goals and plans for teacher } \\
\text { development. }\end{array}$ & .668 & -.033 & .233 & 3.96 & 1.26 \\
\hline $\begin{array}{l}\text { 11. Instructional expectations, standards, and } \\
\text { evaluation protocols are made clear to teachers in } \\
\text { advance. }\end{array}$ & .640 & -.043 & .176 & 4.42 & 1.12 \\
\hline $\begin{array}{l}\text { 13. Teachers receive clear feedback on and } \\
\text { ongoing support for their practice outside of } \\
\text { formal evaluations. }\end{array}$ & .651 & -.030 & .102 & 4.06 & 1.31 \\
\hline $\begin{array}{l}\text { 16. Time is provided in the workday for coaching, } \\
\text { co-planning/co-teaching, and structured } \\
\text { professional learning. }\end{array}$ & .428 & -.081 & -.020 & 3.41 & 1.47 \\
\hline $\begin{array}{l}\text { 2. We have systems where teachers are directly } \\
\text { involved and participate in decision-making and } \\
\text { planning for site initiatives. }\end{array}$ & .011 & -.913 & -.063 & 4.60 & 1.10 \\
\hline $\begin{array}{l}\text { 1. Leadership opportunities are open to all staff } \\
\text { members and staff members are invited to } \\
\text { participate periodically throughout the school } \\
\text { day. }\end{array}$ & -.152 & -.700 & .307 & 4.41 & 1.30 \\
\hline $\begin{array}{l}\text { 3. Administration and leaders communicate } \\
\text { decision-making strategies with staff and elicit } \\
\text { their input. }\end{array}$ & .265 & -.687 & .019 & 4.35 & 1.28 \\
\hline
\end{tabular}


Table 1. Continued

\begin{tabular}{|c|c|c|c|c|c|}
\hline \multirow[b]{2}{*}{ Items } & \multicolumn{3}{|c|}{ Factors } & \multirow[b]{2}{*}{$M$} & \multirow[b]{2}{*}{$S D$} \\
\hline & $\begin{array}{l}\text { Collaborative } \\
\text { Planning } \\
\text { (CP) }\end{array}$ & $\begin{array}{l}\text { Shared } \\
\text { Leadership } \\
\text { (SL) }\end{array}$ & $\begin{array}{l}\text { Open } \\
\text { Communication } \\
\text { and Support (OCS) }\end{array}$ & & \\
\hline $\begin{array}{l}\text { 4. Staff are able to put ideas "on the table" and } \\
\text { "take them off" safely during planning, } \\
\text { collaboration, and decision-making meetings. }\end{array}$ & .450 & -.595 & -.079 & 4.55 & 1.16 \\
\hline $\begin{array}{l}\text { 5. Teachers are invited to give critical feedback } \\
\text { about administrative practices and how they } \\
\text { would like additional support. }\end{array}$ & .214 & -.504 & .131 & 3.87 & 1.38 \\
\hline $\begin{array}{l}\text { 17. Administrators and teachers in our school } \\
\text { truly believe that they can help all students to } \\
\text { meet learning goals. }\end{array}$ & .037 & -.058 & .732 & 4.78 & 1.05 \\
\hline $\begin{array}{l}\text { 19. There is an "us against them" feeling } \\
\text { between teachers and students. }\end{array}$ & -.119 & -.063 & .702 & 4.91 & 1.13 \\
\hline $\begin{array}{l}\text { 10. Our teachers tend to protect or guard our } \\
\text { lessons, strategies, tests, etc. from one another. }\end{array}$ & .072 & .042 & .522 & 4.62 & 1.10 \\
\hline $\begin{array}{l}\text { 9. Teachers collaborate several times a month, } \\
\text { sharing or co-developing lessons, assessments, } \\
\text { and student work. }\end{array}$ & .155 & -.119 & .520 & 4.11 & 1.57 \\
\hline $\begin{array}{l}\text { 7. Teachers observe one another and give each } \\
\text { other feedback to develop the team's best } \\
\text { practices. }\end{array}$ & .280 & .028 & .424 & 3.29 & 1.40 \\
\hline $\begin{array}{l}\text { 6. Staff members are reluctant to work with or } \\
\text { support new or struggling teachers. }\end{array}$ & .140 & -.162 & .414 & 4.80 & .21 \\
\hline $\begin{array}{l}\text { 8. We have exclusive cliques or "camps" within } \\
\text { our faculty. }\end{array}$ & .138 & -.025 & .352 & 3.07 & 1.37 \\
\hline Percent of Variance & 47.04 & 4.66 & 3.53 & & \\
\hline Eigenvalue & 9.42 & 1.37 & 1.24 & & \\
\hline Cronbach alpha & .89 & .88 & .73 & & \\
\hline
\end{tabular}


Both the Comparative Fit Index and the Non-Normed Fit indexes developed by Bentler (1990) are recommended for evaluating model fit because they consider both sample size and model complexity. CFI and NNFI values greater than .90 are indicative of a good model fit. Although, multivariate normality is not a strict assumption of exploratory factor analysis, non-normal multivariate distributions used with CFA have been shown to produce standard errors that are biased downward and inflated chi square values (Costello \& Osborne, 2005). For this analysis, the fit indices were calculated based on Satorra and Bentler (1988) Scaled Chi-Square that is recommended for use with non-normal data.

\subsubsection{Results from the CFA}

The CFA results indicated the hypothesized three factor model $\chi_{(45)}^{2}=95.430, p<.001$ was a superior fit when compared to the independence model $\chi_{(18)}^{2}=244.417, p<.001$ which tests the hypothesis that all variables are uncorrelated. The three-factor model produced an RMSEA of .078. The 90\% confidence interval (.065-.090) surrounding the RMSEA result provided supporting evidence that the proposed model was a "reasonable fit" to the estimated population (Browne \& Cudek, 1993; MacCallum et al., 1996). The "closeness" of this fit to the population model was supported by a CFI of .93 and a NNFI of .92. The factor solution identified by the exploratory analysis was the result of allowing the school mindset factors to correlate. However, the large magnitude of inter-correlations between the three-factor model (shown in Table 2) suggested that a more parsimonious model could be achieved using a second-order school mindset factor according to procedures outlined by Brown (2015).

Table 2. First CFA order factor inter-correlations

\begin{tabular}{|l|l|l|l|}
\hline Factors & Shared Leadership & $\begin{array}{l}\text { Collaborative } \\
\text { Planning }\end{array}$ & $\begin{array}{l}\text { Open Communication } \\
\text { and Support }\end{array}$ \\
\hline Shared Leadership & 1.00 & & \\
\hline Collaborative Planning & .86 & 1.00 & \\
\hline Open Communication and Support & .76 & .76 & 1.00 \\
\hline
\end{tabular}

\subsubsection{Second Order Confirmatory Factor Analysis}

The CFA model with school mindset as the second order factor with the collaborative planning, shared leadership, and open communication and support as sub-factors, was found to be a reasonable fit to the hypothesized hierarchical population model. Results from this analysis yielded a RMSEA of .080. The 90\% confidence interval (.064-.09) surrounding the RMSEA result provided supporting evidence that the proposed model was a "reasonable fit" to the estimated population (Browne \& Cudek, 1993; MacCallum et al., 1996). The accuracy of this fit was supported by a CFI of .93 and a NNFI of .91. These results suggest that the CFA model with school mindset as a second order factor is an equally good fitting model 
(Figure 2 shows the higher order factor model of the CFA). Each of the first order factors loaded strongly onto the second order school mindset factor (range of loadings $=.81-.94$ ) In addition, the higher order school mindset factor was found to explain 65-88 percent of the variance in the three lower order factors. The power for the model fit for both the first and second order CFAs was found to exceed .80 when based on a sample size of 174 (see Kim, 2005). The exploratory factor analysis allowed the school mindset factors to correlate.

\subsubsection{Convergent Validity}

The results of the CFA suggested a unidimensional conceptualization of the school mindset scale with three subfactors. Convergent validity is supported by one overall factor accounting for 65-88 percent of the variance in the three subconstructs. Each individual subfactor is highly correlated with the overall school mindset construct (correlations from .81-.94). The percent of variance across subfactors, explained by the overall mindset factor, and the large factor loadings suggest caution in using the scores of the subscales to interpret their individual influence on the overall school mindset mean score. Similar issues have been reported in survey validation of other social science constructs such as abilities scales (Lane, 2007). Though the subfactors may demonstrate convergent validity by contributing to the overall trait, in this case school mindset, they may not stand alone with valid measurable construct validities when interpreting the results of the scale. Finally, discriminant validity between subfactors was evidenced by their significantly different item loadings on separate factors of the exploratory factor analysis pattern matrix. For example, Table 1 provides evidence of high correlation coefficients $(\geq .30)$ of the items loading on factor 1-collaborative planning ranging from .428 to .745 . This relationship demonstrates empirical evidence of convergent validity of the WMSM scale for the theoretical and extracted factor 1-collaborative planning (Brown, 2015; Gravetter \& Wallnau, 2014).

A review of Table 1, factor loadings of the exploratory factor analysis, showed items loading on factors 2 and 3 also have higher loadings for each unique factor and lower loadings on the other factors meeting the indices set previously. The exceptions would be items 4 and 7 factor loadings do not exceed the loading of another factor by $>.200$ (.595 versus $.450 ; .424$ versus .280 respectively). The constructs may be construed as included in either a formal or informal setting; the items not having discriminated between factors according to the predetermined indices for this study.

\section{Discussion of Results}

The following section provides a discussion comparing the sub-factors identified in the study with the theory.

\subsection{Double-Barreled Items}

Many of the items operationalized in the mindset key features are double-barreled and caution is indicated in interpreting the factor loadings as stable. For example item 14 lists "Teachers, coaches, and administrators work together ... and ... design goals and plans for teacher development." Depending on which aspect of this item a teacher weights more, the item might be viewed as operationalizing behaviors of collaboration, shared leadership, or 


\section{Ml Macrothink}

clear goals and a plan. Each item in factor 2-shared leadership is operationalized using the word "and." Caution is advised to interpret this as a theoretically distinct factor from other items on the scale. For example, item 5, "Teachers are invited to give critical feedback about leadership and management practices and how they would like additional support" operationalizes two constructs in one item. The first half of the item could be weighted most and viewed as shared leadership. The second half of the item could be viewed as operationalizing administrator feedback practices within in the formal system to teachers, similar to the items in key feature 3-supporting development of clear goals and a plan. Item 17, "Administrators and teachers in our school truly believe that they can help all students to meet learning goals," is triple-barreled referring to administrators and teachers together, student support, and belief in the overall performance of the school. This item theoretically could load on any sub-factor identified in this study.

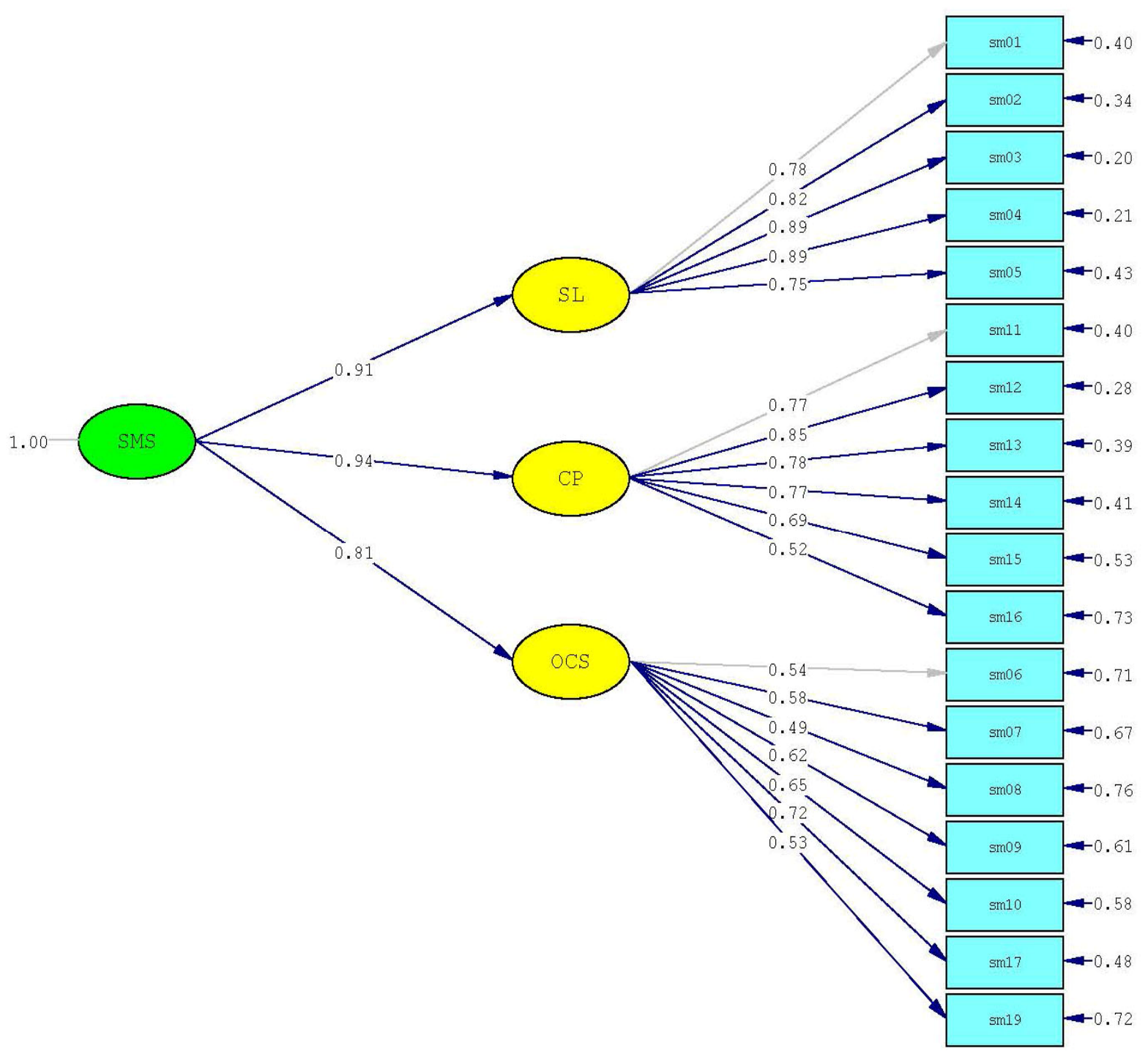

Figure 2. Higher order What's My School Mindset factor structure model 
The above figure provides the results of the CFA. The figure shows three sub-factors of collaborative planning, shared leadership, and open communication \& support that explain the items operationalizing the unidimensional construct of a school growth mindset culture.

\subsection{Factor 1-Collaborative Planning (CP)}

In a comparative analysis of the five key features of a school growth mindset described by Blackwell (2012) two of the key feature items in the mindset literature collapsed into one factor in this analysis. Mindset Works, Inc. key feature 3-clear goals and a plan (items 11, 12, \& 13) operationalizes administrator practices related to teacher feedback and evaluations. Key feature 4-professional collaboration (items 14, 15, \& 16) describes school structures in support of teacher skill development aligned with personal and school goals. The item was renamed collaborative planning to capture the concept of teachers working together in a structured setting toward common goals.

\subsubsection{Development of a Shared Vision}

The Mindset Works, Inc. key features 3 and 4 when combined seem closely related to the concept of a shared vision, as discussed in leadership literature. For example, an enabling school structure promoted school effectiveness by establishing relational trust through organizational routines such that principals and teachers worked together as professional colleagues toward common school goals. This process occurs through formal structured activities within the workday for the faculty to collaborate on the vision, learn the skills necessary to move toward the goals, and structured time in the schedule to work together and practice new learning in the work environment (Hoy \& Sweetland, 2000, 2001).

Shared vision improves schools indirectly and requires teacher collaboration and shared leadership to implement aligned goals and plans. Items 11-13 align with the theoretical concept of administrator organizational citizenship behavior. The administrator's behaviors were found to transform the organizational capabilities while enhancing the social capital (Kianfar, Siadat, Hoveida, \& Abedi, 2013; Tschannen-Moran, 2003). Similarly, under the systems thinking model the items in this sub-factor are similar with the theory of team learning and shared vision. Senge emphasized the inter-relationships within the organization that promoted the development of the organization's collective consciousness, in what he termed shared mental models. Sergiovanni (2009) explained,

Connections among people are made when they are connected to shared ideas and values. Once achieved this binding of people to ideas and this bonding of people together forms a fabric of reciprocal roles, duties, and obligations that are internalized by members of the group (p. 109).

\subsection{Factor 2-Shared Leadership (SL)}

Factor two included items describing willingness of the administrator to give and receive feedback from teachers on administrative practices, largely related to decision-making. Item 1, "Leadership opportunities are open to all staff members," Item 2, "We have systems where teachers are directly involved and participate in decision-making ...," Item 3, 
"Administration and leaders communicate decision-making strategies with staff and elicit their input," Item 4, "Staff are able to put ideas 'on the table' ...," and Item 5, "Teachers are invited to give critical feedback about leadership and management practices and how they would like additional support." This sub-factor was interpreted as shared leadership and was consistent with a review of the WMSM items expected to load together from the five key features of a growth school mindset (Blackwell, 2012). The construct of shared leadership aligns well with concepts found in the literature of systems thinking and enabling school structures and compares favorably to the feature of shared leadership as operationalized in the WMSM Scale. In enabling school structures "principals and teachers work as colleagues while retaining their distinctive roles. Likewise, flexible procedures, not rigid directives, speed the resolution of problems. The structures of the school are designed "to support teachers rather than to enhance principal power" (Tarter \& Hoy, 2004, p. 124). The shared leadership name for this factor was considered reasonable to describe the underlying latent construct and was retained. The interdependence of this sub-factor with the factors 1 and 2 are also described in the literature. For example, shared decision-making would support the development of professional collaboration and in turn develop open communication and trust (Tschannen-Moran, 2003).

\subsection{Open Communication and Support (OCS)}

Factor three included items 6-10, $17 \& 19$ and described teacher perceptions of faculty willingness to support new teachers, share lessons, and an openness to support all teachers and students. Items from student support combined with the items of informal teacher support to create a combined factor named in this study as open communication \& support. A review of the item descriptions revealed supportive and open communication with peers.

\subsubsection{Negatively Worded Items}

The majority of the items in this sub-factor were operationalized with negative wording; "Staff are reluctant to work with or support new or struggling teachers;" "We have exclusive cliques or camps within our faculty;" and "Our teachers tend to protect or guard our lessons...from one another;" and There is an "us against them" feeling between teachers and students" (Mindset Works, 2015a-2015c). Though reverse worded items are meant to overcome the social desirability response tendency (Schutte et al., 1998), Netemeyer et al. (2003) explained another tendency in survey research for negatively worded items to group together, and this must be considered when evaluating this factor.

\subsubsection{Informal Structure and Supportive Behaviors}

Items 7 and 9, captured under factor 3, compared favorably to open communication within the enabling school structure construct. The five key features operationalized items 7 and 9 as, "Teachers observe ... and give each other feedback to develop best practices," and "Teachers collaborate several times a month, sharing or co-developing lessons ..." These items could be interpreted by survey respondents as occurring outside the formal structures of the school, evaluated in this study as part of the informal system within the school organization. This is consistent with Dweck's (2012) school growth mindset concept of mutual support and shared 
knowledge-making also described in the items included in this factor.

Item 17, "Administrators and teachers in our school truly believe that they can help all students to meet learning goals" loaded on this factor revealing the teacher perspective that working together to help students was viewed as a supportive activity. Sergiovanni (2009) wrote, "... teachers, parents and others invest their talents and energy in the school and its children in exchange for certain benefits." "When teachers no longer receive their contacted benefits they are less willing to invest in the school," (p. 108, 109). Senge referenced a report by the Institute for Education and Transformation (Poplin \& Weeres, 1992) explaining school improvements occur through leveraging the relationships between teachers in the school.

\subsubsection{Organizational Citizenship Behaviors}

Informal behaviors demonstrated by individuals in the organization compared favorably to teacher organizational citizenship behaviors (OCB) described in the literature. For example, item 3 on the OCB-Scale (DiPaola \& Hoy, 2005), "Teachers voluntarily help new teachers," compares to item 17 of the WMSM described above. The importance of the informal system of openness and support is its influence on the overall climate and effectiveness of the organization. The process of social identification resulting from informal communications and support generates feelings of belonging and promotes a trusting climate in schools, resulting in increased OCB, collective efficacy, and improved organizational efficiency/outcomes (Berber \& Rofcanin, 2012; DiPaola \& Tschannen-Moran, 2001).

Recognition of an informal school structure has implications for school leaders because leadership styles/behaviors have been shown to influence the creation of open systems that elicit OCB in the organization's members. Organizational citizenship behaviors are employee behaviors that go above and beyond the formal job descriptions of the individual's position (Burns \& Carpenter, 2008; Den Hartog, House, Hanges, Ruiz-Quintanilla, \& Dorfman, 1999; DiPaola, Tarter, \& Hoy, 2005). Open relationships are a feature of the Open Systems model for enabling school structures.

\subsubsection{Changing Factor Named to Include "Support"}

Based on the items that defined factor 3, and a review of the literature, a decision was made to change the factor name to include the term "support." Support indicates an important distinction between communication in the formal structures of the school and the informal relationships between peers (Goddard, 2002; Goddard, Hoy, \& Woolfolk, 2000; Tschannen-Moran \& Hoy, 2000). Factor 3-OCS was shown to compare and contrast to constructs of a culture of trusting and supportive peer relations shown to contribute to improved student achievement (Tarter \& Hoy, 2004). A culture of trust was shown to explain the development of collective efficacy in schools. Collective efficacy is a key component of successful organization as identified by Bandura (2001) in social cognitive theory, a foundational concept of mindset theory. Collective efficacy behaviors of the individuals and the group are supported by an enabling system in the school that supports faculty and administrator behaviors to help each other and to help individual students learn and grow (Blackwell, 2012; Farrington et al., 2012; Hoy \& Miskel, 2005; PERTS, 2014; 
Tschannen-Moran, 2003).

\section{Conclusion}

This study used statistical analyses and a review of the literature to discover valid psychosocial factors that are related to organizational learning and operationalized on the WMSM scale described as a school mindset culture. The results of this study suggested the WMSM scale is a unidimensional scale comprised of three subfactors, collaborative planning, shared leadership, and open communication \& support. The unidimensional factor of school mindset compared favorably with the theory on learning organizations and enabling school structures in Open Systems theory (Senge, 1990; Tarter \& Hoy, 2004). The second order factor, school mindset, was shown to be a reliable and valid construct that demonstrated convergent validity; explaining 65-88 percent of the variance in the three subconstructs. Each individual subfactor was highly correlated with the overall school mindset construct (correlations from .81-.94). Convergent and discriminant validity of the subfactors was demonstrated by significant differences between the loadings on the EFA.

\subsection{Limitations}

Though this study was performed using a sample including mostly rural, white demographic in school sizes under 1,500 the identification of a unidimensional second-order, three-subfactor model were replicated on a study using medium school sizes in a rural population with a varied cultural demographic (Hanson, in progress a).

\subsection{Implications}

Effective use of reflective practices begins with collecting sound data of faculty's perceptions of their school culture. Implications of the study suggest principals can compare their overall school mindset scale results to the means of schools from the data provided in this study to evaluate their teachers perceptions of their school culture. Data provided by the teacher self-reports can provide opportunities for beginning dialogues with faculty, staff, and stakeholders.

\subsection{Recommendations for Future Research}

The sub-factors identified in the WMSM scale are highly interrelated and many of the items are double-barreled or triple-barreled and may be difficult to theoretically separate as one construct. Recommendations include reviewing these items and separating out the separate constructs into two single construct items. A separate factor for student support was not identified as purported in the five key features of a school growth mindset. Though goal setting for teacher professional development is identified operationalized items for goal alignment are not included in the WMSM scale. Alignment between district, school, and inclusive and equitable classroom goals for all students is a critical component of organizational behaviors that help all students learn and grow. A separate study was performed using additional scale items operationalizing goal alignment. The study revealed goal alignment has a significant and large effect on variations in the school mindset mean (Hanson, in progress a). Additional research recommended would be to correlate learning 
organization constructs with individual student psychosocial factors of intelligence beliefs, belonging, relevance, and efficacy operationalized on the Project for Educational Research that Scales (Hanson, in progress b; PERTS, 2014) instrument.

\section{References}

Adams, J. (2014). Measuring a 'growth mindset' in a new school accountability system. EdSource. Retrieved April 15, 2015, from http://edsource.org/2014/measuring-a-growthmindset-in-a-new-school-accountability-system/63557\#.VS2yP5NKY6E

Bandura, A. (1977). Social learning theory. Englewood Cliffs, N.J.: Prentice-Hall

Bandura, A. (2001). Social cognitive theory: An agentic perspective. Annual Review of Psychology, 52, 1-26. http://dx.doi.org/10.1146/annurev.psych.52.1.1

Baumeister, R., Masicampo, E., \& Vohs, K. (2011). Do conscious thoughts cause behavior? Annu. Rev. Psychol., 62(1), 331-361. http://dx.doi.org/10.1146/annurev.psych.093008.131126

Bentler, P. M. (1990). Comparative fit indexes in structural models. Psychological Bulletin, 107, 238-246. http://dx.doi.org/10.1037/0033-2909.107.2.238

Berber, A., \& Rofcanin, Y. (2012). Investigation of organization citizenship behavior construct a framework for antecedents and consequences. International Journal of Business and Social Research, 2(4), 195-210.

Blackwell, L. (March 28, 2012). Developing a growth mindset school culture. Mindset Works' Blog: Cultivating Growth Mindsets. Retrieved October 26, 2016, from http://blog.mindset works.com/blog-page/home-blogs/entry/developing-a-growth-mindset-school-culture-2-ar

Brown, J. D. (2009). Choosing the right type of rotation in pca and efa. Shiken. JALT Testing \& Evaluation SIG Newsletter, 13(3), 20-25. Retrieved September 28, 2016, from http://jalt.org/test/PDF/Brown31.pdf

Brown, T. A. (2015). Confirmatory factor analysis for applied research (2nd ed.). New York: Guilford Press.

Browne, M. W., \& Cudeck, R. (1993). Alternative ways of assessing model fit. In K. A. Bollen, \& J. S. Long (Eds.), Testing Structural Equation Models (pp. 136-192). Newbury Park, CA: Sage.

Burnette, J. L., O’boyle, E. H., Vanepps, E. M., Pollack, J. M., \& Finkel, E. J. (2013). Mind-sets matter: A meta-analytic review of implicit theories and self-regulation. Psychological Bulletin, 139(3), 655-701. http://dx.doi.org/10.1037/a0029531

Burns, T., \& Carpenter, J. (2008). Organizational citizenship and student achievement. Journal of Cross-Disciplinary Perspectives in Education, 1(1), 51-58. Retrieved September 28, 2016, from http://www.resnet.wm.edu/ mxtsch/Teaching/JCPE/Volume1/JCPE_200801-08.pdf

Byrne, B. M. (1998). Structural equation modeling with lisrel, prelis and simplis: Basic 
concepts, applications and programming. Mahwah, NJ: Erlbaum.

Costello, A. B., \& Osborne, J. W. (2005). Best practices in exploratory factor analysis: Four recommendations for getting the most from your analysis. Practical Assessment, Research \& Evaluation, 10(7), 1-9. Retrieved September 28, 2016, from http://pareonline.net/pdf/ v10n7.pdf

Den Hartog, D. N., House, R. J., Hanges, P. J., Ruiz-Quintanilla, S. A., Dorfman, P. W., \& Field, R. (1999). Culture specific and cross-culturally generalizable implicit leadership theories: Are attributes of charismatic/transformational leadership universally endorsed? Leadership Quarterly, 10(2), 219-224. http://dx.doi.org/10.1016/S1048-9843(99)00018-1

DiPaola, M. F., \& Hoy, W. K. (2005). School characteristics that foster organizational citizenship behavior. Journal of School Leadership, 15(4), 387-406. Retrieved September 28, 2016 from https://www.researchgate.net/publication/234650814_School_Characteristics that_Foster_Organizational_Citizenship_Behavior

DiPaola, M. F., Tarter, C. J., \& Hoy, W. K. (2005). Measuring organizational citizenship of schools: The OCB scale. In W. Hoy, \& C. Miskel (Eds.), Educational Leadership and Reform (Vol. 4, pp. 319-341). Greenwich, CN: Information Age Publishing.

DiPaola, M., \& Tschannen-Moran, M. (2001). Organizational citizenship behavior in schools and its relationship to school climate. Journal of School Leadership, 11(5), 424-447. Retrieved September 28, 2106, from http://mxtsch.people.wm.edu/Scholarship/JSL_OCBand Climate.pdf

Duckworth, A. L., \& Yeager, D. S. (2015). Measurement matters: Assessing personal qualities other than cognitive ability for educational purposes. Educational Researcher, 44(4), 237-251. http://dx.doi.org/10.3102/0013189X15584327

Dweck, C. (1986). Motivational processes affecting learning. American Psychologist, 41(10), 1040-1048. http://dx.doi.org/10.1037/0003-066X.41.10.1040

Dweck, C. S. (2008). Mindset: The new psychology of success. New York: Ballantine

Dweck, C. S. (2010). Mind-sets and equitable education. Principal Leadership, 26-29. Retrieved October 26, 2016, from http://www.greatschoolspartnership.org/wp-content/ uploads/2014/11/Mindsets-and-Equitable-Education.pdf

Dweck, C. S. (2012). Mindsets and human nature: Promoting change in the Middle East, the schoolyard, the racial divide, and willpower. American Psychologist, 67(8), 614-622. http://dx.doi.org/10.1037/a0029783

Fabrigar, L. R., Wegener, D. T., MacCallum, R. C., \& Strahan, E. J. (1999). Evaluating the use of exploratory factor analysis in psychological research. Psychological Methods, 4(3), 272-299. http://dx.doi.org/10.1037/1082-989X.4.3.272

Farrington, C. A., Roderick, M., Allensworth, E., Nagaoka, J., Seneca-Keyes, T. S., Johnson, D. W., \& Beechum, N. O. (2012). The role of noncognitive factors in shaping school 
performance: A critical literature review. Teaching adolescents to become learners. Chicago: University of Chicago Consortium on Chicago School Research. Retrieved October 25, 2016, from https://consortium.uchicago.edu/sites/default/files/publications/Noncognitive\%20Report. pdf

Field, A. (2000). Discovering statistics using spss for windows. London-Thousand Oaks-New Delhi:Sage publications.

Field, A. (2009). Discovering statistics using SPSS. London: SAGE.

Goddard, R. D. (2002). A theoretical and empirical analysis of the measurement of collective efficacy: The development of a short form. Educational and Psychological Measurement, 93, 467-476. http://dx.doi.org/10.1177/0013164402062001007

Goddard, R. D., Hoy, W. K., \& Woolfolk, A. (2000). Collective faculty efficacy: Its meaning, measure, and effect on student achievement. American Education Research Journal, 37(2), 479-507. http://dx.doi.org/10.3102/00028312037002479

Gravetter, F., \& Wallnau, L. (2014). Essentials of statistics for the behavioral sciences (8th ed.). Belmont, CA: Wadsworth.

Guilford, J. P. (1954). Psychometric methods (2nd ed.). New York: McGraw-Hill.

Hanson, J. L. (2015). Determination and validation of the "What's My School Mindset?" instrument factor structure (Order No. 3722197). Dissertations \& Theses at Montana State University; ProQuest Dissertations \& Theses Global.

Hanson, J. L. (in press). Mindset: Why and how it works. Lanham, MD: Rowman \& Littlefield.

Hanson, J. L. (in progress a). A replication study of the validation of the What's My School Mindset? survey.

Hanson, J. L. (in progress b), Measuring student perceptions of non-cognitive factors to develop student agency for academic behaviors.

Hanson, J., Bangert, A., \& Ruff, W. (2016). Exploring the relationship between school growth mindset and organizational learning variables: Implications for multicultural education. Journal of Educational Issues, 2(2), 222-243. http://dx.doi.org/10.5296/jei.v2i2.10075

Hofkirchner, W. (n.d). General system theory. Unified Theory of Information Research Group. Retrieved September 27, 2016, from http://www.hofkirchner.uti.at/wp-content/uploads/2010/ 10/GSTcombined.pdf

Hong, Y., Morris, M. W., Chiu, C., \& Benet-Martínez, V. (2000). Multicultural minds: A dynamic constructivist approach to culture and cognition. American Psychologist, 55(7), 709-720. http://dx.doi.org/10.1037/0003-066X.55.7.709

Hoy, W. K., \& Sweetland, S. R. (2000). School bureaucracies that work: Enabling, not coercive. Journal of School Leadership, 10, 524-541. 
Hoy, W. K., \& Sweetland, S. R. (2001). Designing better schools: The meaning and measure of enabling school structures. Educational Administration Quarterly, 37(3), 296-321. http://dx.doi.org/10.1177/00131610121969334

Hoy, W., \& Miskel, C. (Eds.). (2005). Educational leadership and reform. Greenwich, Conn.: Information Age Publishing.

Hoy, W., Tarter, C., \& Kottkamp, B. (1991). Open schools/healthy schools measuring organizational climate. Newbury Park: Sage Publications.

Jöreskog, K. G. (1999). How large can a standardized coefficient be. Unpublished Technical Report. Retrieved June 5, 2015, from http://www.ssicentral.com/lisrel/techdocs/HowLarge CanaStandardizedCoefficientbe.pdf

Jöreskog, K. G., \& Sörbom, D. (2015). LISREL (version 9.2) [Computer Software]. Chicago: Scientific Software, Inc.

Kearney, S. (2007). Principal influence: A study of its effect on school change. The University of Texas at San Antonio, ProQuest.

Kianfar, V., Siadat, S. A., Hoveida, R., \& Abedi, A. (2013). Investigating structural relation of organizational trust and organizational citizenship behavior to intellectual capital at state university in the west of Iran. International Journal of Learning and Development, 3(4), 114-122. http://dx.doi.org/10.5296/ijld.v3i4.4248

Kim, K. H. (2005). The relation among fit indexes, power, and sample size in structural equation modeling. Structural Equation Modeling, 12(3), 368-390. http://dx.doi.org/10.1207/ s15328007sem1203_2

Lane, A. (2007). Mood and human performance: Conceptual, measurement, and applied issues. Nova Publishers. Retrieved September 28, 2016, from https://webcache.googleuser content.com/search?q=cache:9EFNwVns3D0J:https://www.novapublishers.com/catalog/prod uct_info.php\%3Fproducts_id \%3D4553+\&cd=1\&hl=en\&ct=clnk\&gl=us

Leithwood, K., Anderson, S., Louis, K. S., \& Wahlstrom, K. (2004). How leadership influences student learning. Wallace Foundation. Retrieved October 26, 2016, from http://www.wallacefoundation.org/knowledge-center/Documents/How-Leadership-Influences -Student-Learning.pdf

MacCallum, R. C., Browne, M. W., \& Sugawara H. M. (1996). Power analysis and determination of sample size for covariance structure modeling. Psychological Methods, 1, 130-49. http://dx.doi.org/10.1037/1082-989X.1.2.130

Martin, J. (1979). Self-regulated learning, social cognitive theory, and agency. Educational Psychologist, 39(2), 135-145. http://dx.doi.org/10.1207/s15326985ep3902_4

Meador, D. (2015). Profile on Montana education and schools. Retrieved April 23, 2015, from http://teaching.about.com/od/ProfilesInEducation/a/Montana-Education.htm

Mindset Works, Inc. (2015a). Promoting a culture of ongoing learning and growth. 
Mindsetworks. Retrieved October 26, 2016, from http://www.mindsetworks.com/webnav/ about.aspx

Mindset Works, Inc. (2015b). Dr. Dweck's discovery of fixed and growth mindsets have shaped our understanding of learning. Retrieved October 26, 2016, from http://www.mindsetworks. com/webnav/whatismindset.aspx

Mindset Works, Inc. (2015c). What's My School Mindset? (para. 5). Retrieved October 26, 2016, from https://www.mindsetworks.com/assess/

Netemeyer, R. G., Bearden, W. O., \& Sharma, S. (2003). Scaling procedures: Issues and applications. Thousand Oaks: Sage Publications. http://dx.doi.org/10.4135/9781412985772

Panorama Education. (2014). CORE SEL pilot overview for district pilot coordinators. CORE Collaboration Central. Retrieved September 28, 2016, from http://collaborate.caedpartners. org/display/CAED/CORE+SEL+Pilot+Overview+for+District+Pilot+Coordinators

PERTS. (2016). Education research at scale. PERTS. Retrieved October 26, 2016, from https://www.perts.net/

Poplin, M., \& Weeres, J. (1992). Voices from the inside. The Institute for Education in Transformation. Retrieved October 26, 2016, from http://www.cgu.edu/PDFFiles/poplin/ Voices-BW.pdf

Satorra, A., \& Bentler, P. M. (1988). Scaling corrections for chi-square statistics in covariance structure analysis. In ASA 1988 Proceedings of the Business and Economic Statistics, Section (308-313). Alexandria, VA: American Statistical Association.

Schutte, N. S., Malouff, J. M., Hall, L. E., Haggerty, D. J., Cooper, J. T., Golden, C. J., et al. (1998). Development and validation of a measure of emotional intelligence. Personality and Individual Differences, 25, 167-177.http://dx.doi.org/10.1177/0146167204272860

Senge, P. (2000). Schools that learn: A fifth discipline fieldbook for educators, parents, and everyone who cares about education. New York, NY: Doubleday.

Senge, P. M. (1990, revised 2006). The fifth discipline: The art \& practice of the learning organization. New York, NY: Doubleday.

Sergiovanni, T. J. (2009). The principalship: A reflective practice perspective. Boston: Pearson.

Spencer-Rodgers, J., Williams, M. J., \& Peng, K. (2012). Culturally based lay beliefs as a tool for understanding intergroup and intercultural relations. International Journal of Intercultural Relations, 36(2), 169-178. http://dx.doi.org/10.1016/j.ijintrel.2012.01.002

Stevens, J. (2002). Applied Multivariate Statistics for the Social Sciences (4th ed.). Mahwah, NJ: Lawrence Erlbaum Associates.

Strahan, E. J., Spencer, S. J., \& Zanna, M. P. (2002). Subliminal priming and persuasion: Striking while the iron is hot. Journal of Experimental Social Psychology, 38(6), 556-568. 


\section{Macrothink}

http://dx.doi.org/10.1016/S0022-1031(02)00502-4

Tarter, C., \& Hoy, W. (2004). A systems approach to quality in elementary schools: A theoretical and empirical analysis. Journal of Educational Administration, 42(5), 539-554. http://dx.doi.org/10.1108/09578230410554052

Thomas, K., \& Allen, S. (1994). The learning organisation: A meta-analysis of themes in literature. The Learning Organization, 13(2), 123-139. http://dx.doi.org/10.1108/0969647061 0645467

Tschannen-Moran, M. (2003). Fostering organizational leadership: Transformational leadership and trust. In W. K. Hoy \& C. G. Miskel (Eds.), Studies in leading and organizing schools (pp. 157-179). Information Age Publishing: Greenwich.

Tschannen-Moran, M., \& Hoy, W. K. (2000). A multidisciplinary analysis of the nature, meaning, and measurement of trust. Review of Educational Research, 70(4), 547-593. http://dx.doi.org/10.3102/00346543070004547

Von Bertalanffy, L. (1950). The theory of open systems in physics and biology. Science, 111(2872), 23-29. http://dx.doi.org/10.1126/science.111.2872.23

Walton, G. M. (2014). The new science of wise psychological interventions. Current Directions in Psychological Science, 23(1), 73-82. http://dx.doi.org/10.1177/0963721413512856

Weschler, D. (1943). Non-intellective factors in general intelligence. Journal of Abnormal and Social Psychology, 38(1), 101-103. http://dx.doi.org/10.1037/h0060613

Woike, B. A. (2008). A functional framework for the influence of implicit and explicit motives on autobiographical memory. Personality and Social Psychology Review, 12(2), 99-117. http://dx.doi.org/10.1177/1088868308315701

Zhao, N. (March 23, 2009). The minimum sample size in factor analysis. Wiki of Encorelab Toronto. Retrieved September 28, 2016, from https://www.encorewiki.org/display/ nzhao/ The+Minimum+Sample+Size+in+Factor+Analysis

\section{Copyright Disclaimer}

Copyright for this article is retained by the author(s), with first publication rights granted to the journal.

This is an open-access article distributed under the terms and conditions of the Creative Commons Attribution license (http://creativecommons.org/licenses/by/3.0/). 